\title{
MAPEAMENTO DAS UNIDADES DE PAISAGEM DO ESTADO DO RIO GRANDE DO NORTE, BRASIL
}

\author{
MAPPING OF THE LANDSCAPE UNITS OF THE \\ STATE OF RIO GRANDE DO NORTE, BRAZIL \\ MAPEO DE LAS UNIDADES DE PAISAJE DEL ESTADO \\ DE RIO GRANDE DO NORTE, BRASIL \\ Marco Túlio Mendonça Diniz - Universidade Federal do Rio Grande \\ do Norte - Natal - Rio Grande do Norte - Brasil \\ tuliogeografia@gmail.com \\ Antônia Vilaneide Lopes Costa de Oliveira - Universidade Federal do Rio
Grande do Norte - Natal - Rio Grande do Norte - Brasil
vilaneide_oliveira@yahoo.com.br
}

\section{Resumo}

0 mapeamento de unidades de paisagem é fundamental para o ordenamento do território, pois se trata de etapa preliminar para o zoneamento ecológico-econômico. 0 objetivo deste trabalho foi realizar o mapeamento das unidades de paisagem na escala dos geocomplexos para o estado do Rio Grande do Norte. A pesquisa foi organizada no sistema taxonômico proposto por Bertrand (1972) e utilizado por Ab'Sáber (2003) para o território nacional e por Souza (2000) para o estado do Ceará. 0 mapeamento foi realizado em escala de 1:250.000. Foram identificados e mapeados 20 geocomplexos, nove regióes naturais e dois domínios morfoclimáticos para o estado do Rio Grande do Norte. Espera-se que este estudo seja utilizado posteriormente como base para o planejamento e 0 ordenamento do território.

Palavras-chave: Unidades de paisagem, paisagem integrada, unidades geoambientais.

\section{Abstract}

The mapping of landscape units is fundamental for spatial planning, since this is the preliminary stage for the Ecological-Economic Zoning. The objective of this work was to map the landscape units on the scale of geocomplexes for the State of Rio Grande do Norte. The research was organized in the taxonomic system proposed by Bertrand (1972) and used by Ab'Sáber (2003) for the national territory and by Souza (2000) for the State of Ceará. The mapping was performed at a scale of 1: 250,000. Twenty geocomplexes, nine natural regions and two morphoclimatic domains were identified and mapped for the state of Rio Grande do Norte. It is hoped that this study will be used later as a basis for planning and planning of the territory.

Keywords: Landscape units, integrated landscape, geoenvironmental units.

\section{Resumen}

El mapeamiento de unidades de paisaje es fundamental para el ordenamiento del territorio, pues se trata de etapa preliminar para la Zonificación Ecológico-Económica. El objetivo de este trabajo fue realizar el mapeo de las unidades de paisaje en la escala de los geocomplejos para el Estado de Rio Grande do Norte. La investigación fue organizada en el sistema taxonómico propuesto por Bertrand (1972) y utilizado por Ab'Sáber (2003) para el territorio nacional y por Souza (2000) para el Estado de CearáEl mapeo se realizó a una escala de 1: 250.000 . Se identificaron y mapearon veinte geocomplejos, nueve regiones naturales y dos dominios morfoclimáticos para 
Artigo

el estado de Rio Grande do Norte. Se espera que este estudio sea utilizado posteriormente como base para la planificación y ordenación del territorio.

Palabras clave: Unidades de paisaje, paisaje integrado, unidades geoambientales.

Introdução

A compartimentação das unidades de paisagem se insere no rol dos estudos da dinâmica das paisagens e se apresenta como um instrumento de planejamento ambiental e ordenamento territorial fundamentado em técnicas integradoras das informações ambientais.

No estado do Rio Grande do Norte, existe uma obra de referência, que parte dessa abordagem da compartimentação. Essa obra é fruto de um trabalho técnico encomendado pelo Instituto de Desenvolvimento Sustentável e Meio Ambiente (IDEMA). O referido trabalho foi executado em 2006 com a publicação de relatório técnico neste ano (IDEMA, 2006) e posteriormente publicado no meio científico-acadêmico por Cestaro et al. (2007), a equipe técnica que elaborou o mapa. Esse material se refere ao mapeamento das unidades geoambientais do estado supracitado. Na Figura 1, é possível identificar esse mapeamento realizado pelo IDEMA (2006). 


\section{RIO GRANDE DO NORTE} MAPA DO GEOSSISTEMA

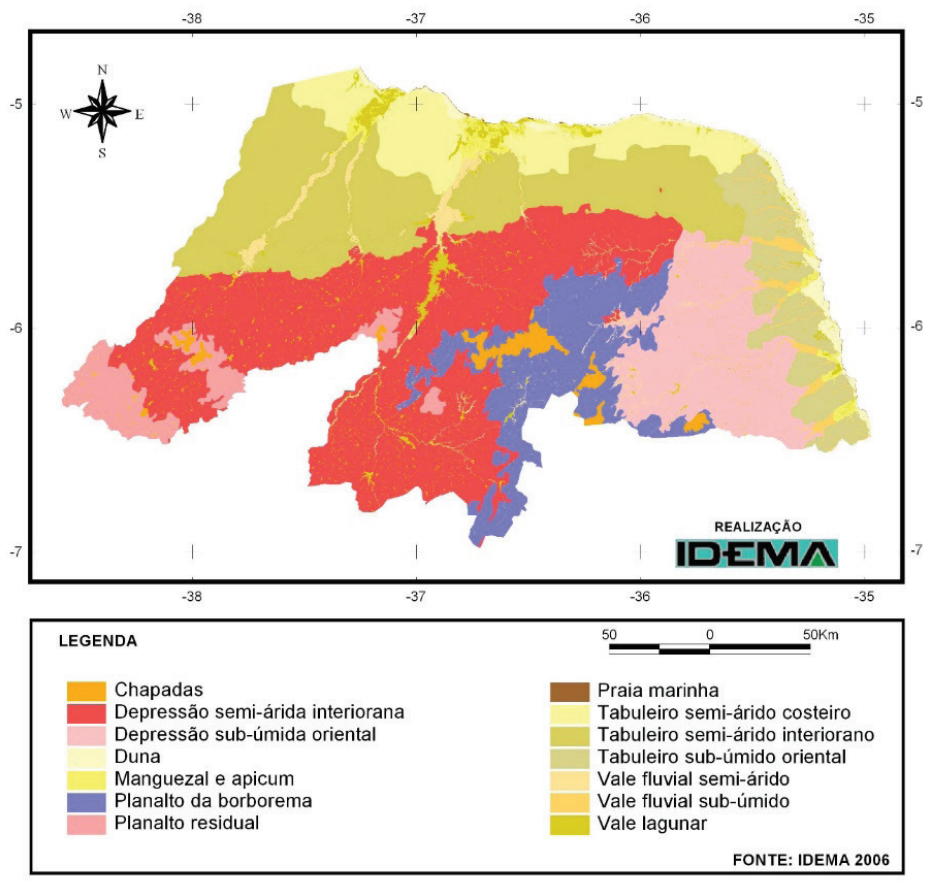

Figura 1 - Mapa do Geossistema do Rio Grande do Norte Fonte: IDEMA, 2006.

Assim, considerando que alguns pontos específicos não estavam de acordo com as principais obras de referência sobre o tema, esta pesquisa pretendeu atualizar e aperfeiçoar, uma década depois, o mapeamento do IDEMA (2006) e de Cestaro et al. (2007). Nesse sentido, para o norteamento da pesquisa que resultou neste artigo, foram considerados os seguintes pressupostos como avanços em relação ao mapeamento anterior:

1. tomar por referência o geossistema como categoria de análise e o geocomplexo como unidade taxonômica, conforme apontado por Beroutchachvili e Bertrand (1978); 
2. considerar a existência de dois domínios morfoclimáticos no estado, conforme Ab’Sáber (2003), e não levados em conta no mapeamento anterior;

3. dividir os domínios morfoclimáticos em regiões naturais, não apresentadas anteriormente;

4. dividir as regiões naturais em geocomplexos;

5. redimensionar algumas unidades que aparentemente se encontram superestimadas - como o geossistema da depressão semiárida interiorana -, subdividindo-as (em geocomplexos menores) ou agrupando-as em outras unidades - como no caso do geossistema manguezal e apicum (CESTARO et al., 2007; Figura 1);

6. criar uma base de informações necessária ao posterior zoneamento ecológico-econômico (ZEE) do estado, uma vez que este não existe.

Desse modo, o objetivo deste trabalho foi mapear as unidades de paisagem do Rio Grande do Norte em escala de 1:250.000.

\section{Metodologia}

O estado do Rio Grande do Norte está localizado no extremo Nordeste do Brasil (Figura 2), aproximadamente entre as coordenadas $4^{\circ}$ $50^{\prime} \mathrm{S}$ e $6^{\circ} 59^{\prime} \mathrm{S}$; e $34^{\circ} 58^{\prime} \mathrm{O}$ e $38^{\circ} 34^{\prime} \mathrm{O}$. É um dos nove estados da região Nordeste do Brasil e limita-se a oeste com o Ceará, ao sul com a Paraíba e a norte e a leste com o Oceano Atlântico. Em 2013, a população estimada para o estado era de 3.373.959 habitantes (IBGE, 2013). 


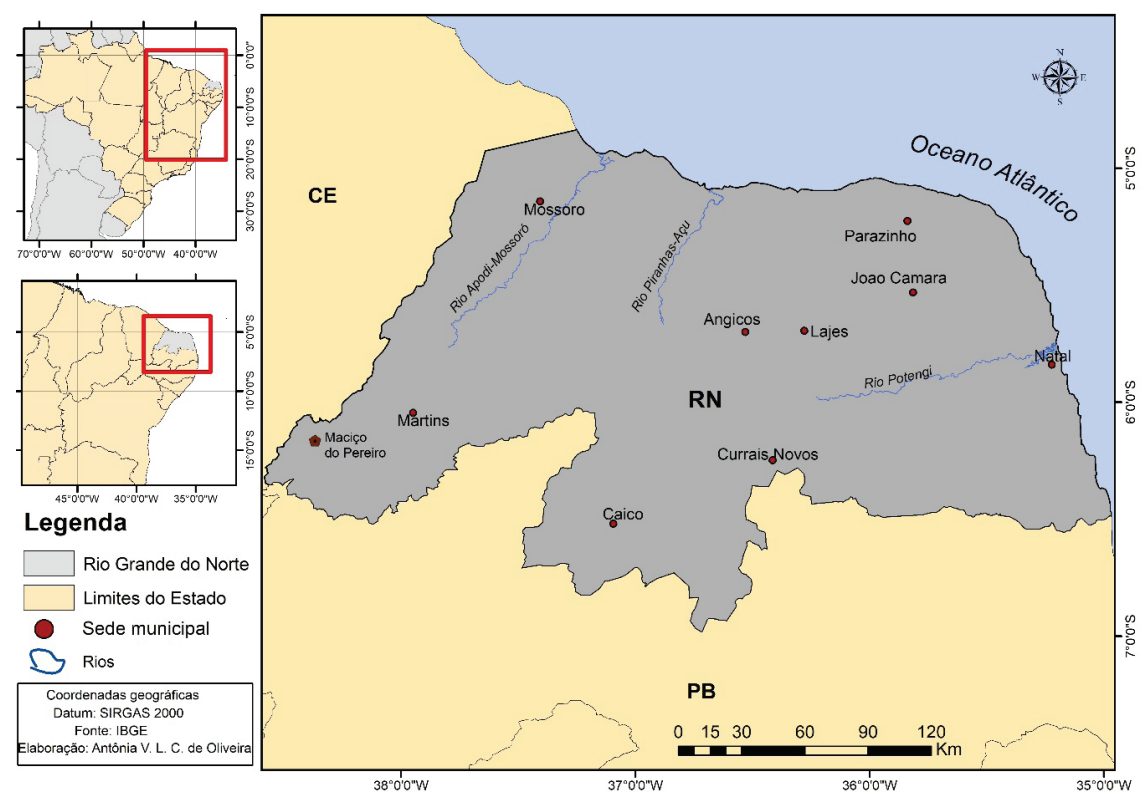

Figura 2 - Mapa de localização do estado do Rio Grande do Norte.

Fonte: Elaborado pelos autores (2018)

George Bertrand (1972) apresentou um texto de referência com grande repercussão na Geografia brasileira. A obra teve como maior contribuição a elaboração de um sistema taxonômico universal que permite classificar as paisagens na dupla perspectiva do espaço e do tempo. O referido autor destaca que a noção de escala é inseparável do estudo das paisagens, utilizando na sua metologia de trabalho as escalas têmporo-espaciais de Cailleux e Tricart (1956).

Conforme Bertrand (1972), na delimitação das paisagens, as unidades superiores são: zona, domínio e região natural; já as inferiores são: geossistema, geofácies e geótopo.

Cabe destacar que, contrariamente à concepção original de Bertrand, a ideia de geossistema está além de um simples nível hierárquico, fato que já havia sido mostrado por V. B. Sochava (1977). Bertrand (Beroutchachvilli; Bertrand, 1978), na tentativa de criar um consenso com relação às terminologias empregadas pelos estudiosos da paisagem, admite que a definição mais lógica de geossistema é a proposta por Sochava (1977), 
sendo o geossistema, da mesma maneira que o ecossistema, uma abstração e uma categoria de análise que não se detém a uma mera escala espacial arbitrária, de forma que o geocomplexo passou a ser uma escala de análise geográfica e o geossistema, o próprio conceito base de sua teoria, ou seja, dos estudos da Geografia Física Global. Pode-se inclusive afirmar que o geossistema está para a Geografia Física Global assim como o ecossistema está para a Ecologia.

Assim, como nível taxonômico que pudesse substituir a nomenclatura geossistema, surge o geocomplexo, ou complexo geográfico, que está bem definido na escala têmporo-espacial ( $4^{\mathrm{a}}$ e $5^{\mathrm{a}}$ grandezas). Nessa escala, evoluem as combinações dialéticas mais interessantes para o geógrafo (Bertrand, 1972), compatíveis com a escala humana. O homem, o potencial ecológico (fatores abióticos: geomorfologia, clima, hidrologia) e a exploração biológica (fatores bióticos: vegetação, solo, fauna) produzem a síntese dessa dialética da paisagem.

O critério principal para a definição do geocomplexo é o mesmo proposto por Bertrand (1972) para a definição do geossistema, ou seja, a vegetação. Entretanto, ele acrescenta que, para alguns casos, o elemento dominante pode vir a ser a geomorfologia. Esse critério é bastante adotado nas pesquisas de Aziz Nacib Ab’Sáber (1969) e Marcos José Nogueira de Souza (2000), que utilizam a hierarquização proposta por Bertrand (1972).

Souza (2000) foi responsável pela delimitação das unidades de paisagem do estado do Ceará. O autor considera a geomorfologia mais constante para a delimitação de sistemas ambientais, já que a vegetação do semiárido brasileiro (o mais povoado do mundo) foi, e ainda é, fortemente alterada pelo homem. Ab'Sáber, por sua vez, foi orientador de Souza e se preocupou com a classificação das paisagens em âmbito nacional, propondo os Domínios Morfoclimáticos e Fitogeográficos do Brasil em uma série de trabalhos compilados em Ab’Sáber (2003). Ambas as obras tiveram seus mapeamentos como referências para este trabalho.

Foi utilizado o sistema taxonômico de Bertrand (1972), por sua aplicação universal, de modo que pode ser empregado para o mapeamento de unidades de paisagem em todo o globo, de acordo com a escala de detalhamento escolhida pelo pesquisador. Como já foi dito, o sistema considera da maior para a menor unidade, propondo as unidades Zona, Domínio, Região Natural, Geocomplexos, Geofácies e Geotópos. Esse 
mapeamento foi realizado em escala de 1:250.000, avançando até o nível dos geocomplexos.

Foram mapeados os domínios morfoclimáticos e fitogeográficos apontados por Ab'Sáber (2003) que ocupam o território potiguar, além de uma área de transição entre esses dois domínios, comumente denominada Agreste. O Domínio das Depressões Interplanálticas Semiáridas do Nordeste (vegetado por caatingas) ou Domínio das Caatingas foi mapeado em tons de cor amarelo, marrom e cinza e o Domínio dos "Mares de Morros" Florestados ou Domínio da Mata Atlântica teve tons de verde. Esses dois domínios foram separados com base na pluviometria média mapeada por Diniz e Pereira (2015). Já as regiões naturais são divisões desses domínios com base nas unidades geológicas de Angelim, Medeiros e Nesi (2006) e nos domínios morfoesculturais de Diniz et. al. (2017).

O domínio da Mata Atlântica está posicionado na parte extrema leste do estado, envolvido pela isoieta de $1000 \mathrm{~mm}$ que praticamente coincide com a delimitação dos subtipos de clima úmido e semiúmido do estado. Existe uma área de transição de clima semiárido brando (seis meses secos) imediatamente a oeste do domínio anterior, que foi delimitada entre as isoietas de 800 e 1000 mm. Já o Domínio das Caatingas está posicionado a oeste da área de transição, sob clima semiárido que varia de brando (seis meses secos) a forte (sete a oito meses secos), em sua maior parte dentro da isoieta de $800 \mathrm{~mm}$, à exceção das áreas mais elevadas do oeste do estado.

As temperaturas médias em todo o estado têm pequena variação, com médias entre $23^{\circ} \mathrm{C}$ e $26^{\circ} \mathrm{C}$, uma vez que é mínima a variação longitudinal, e a altitude supera os $700 \mathrm{~m}$ apenas em áreas restritas. Por isso, a temperatura não é um componente relevante para a delimitação de Domínios Morfoclimáticos.

Foram utilizados como base cartográfica o mapeamento de solos da Sudene (1971), de clima de Diniz e Pereira (2015), geomorfológico de Diniz et al. (2017), de vegetação de Kuhlmann (1977), geológico de Angelim, Medeiros e Nesi (2006), além de imagens do software Google Earth do ano de 2016 e imagens de Radar SRTM (Shuttle Radar Topography Mission) pós-processadas pelo projeto “Topodata” do Instituto Nacional de Pesquisas Espaciais (INPE). Toda a base foi georreferenciada em coordenadas geográficas no Datum SIRGAS 2000. Para o mapeamento, utilizaram-se os softwares ENVI 5.1 e ArcGIS 10.2, ambos com licenças acadêmicas. Ao longo dos anos de 2016 e 2017, foram feitas diversas expedições de campo 
para validar o mapeamento, que foi financiado pelo Conselho Nacional de Desenvolvimento Científico e Tecnológico (CNPq).

Resultados e discussão

Domínios morfoclimáticos

Foram delimitados dois domínios morfoclimáticos e uma área de transição identificados por Ab’Sáber (2003). Os dois domínios foram denominados pelo autor por Domínio das Depressões Interplanálticas Semiáridas do Nordeste (vegetado por caatingas) ou Domínio das Caatingas e Domínio dos "Mares de Morros" Florestados ou Domínio da Mata Atlântica (Figura 3). 


\section{DOMÍNIOS MORFOCLIMÁTICOS DO ESTADO DO RIO GRANDE DO NORTE}

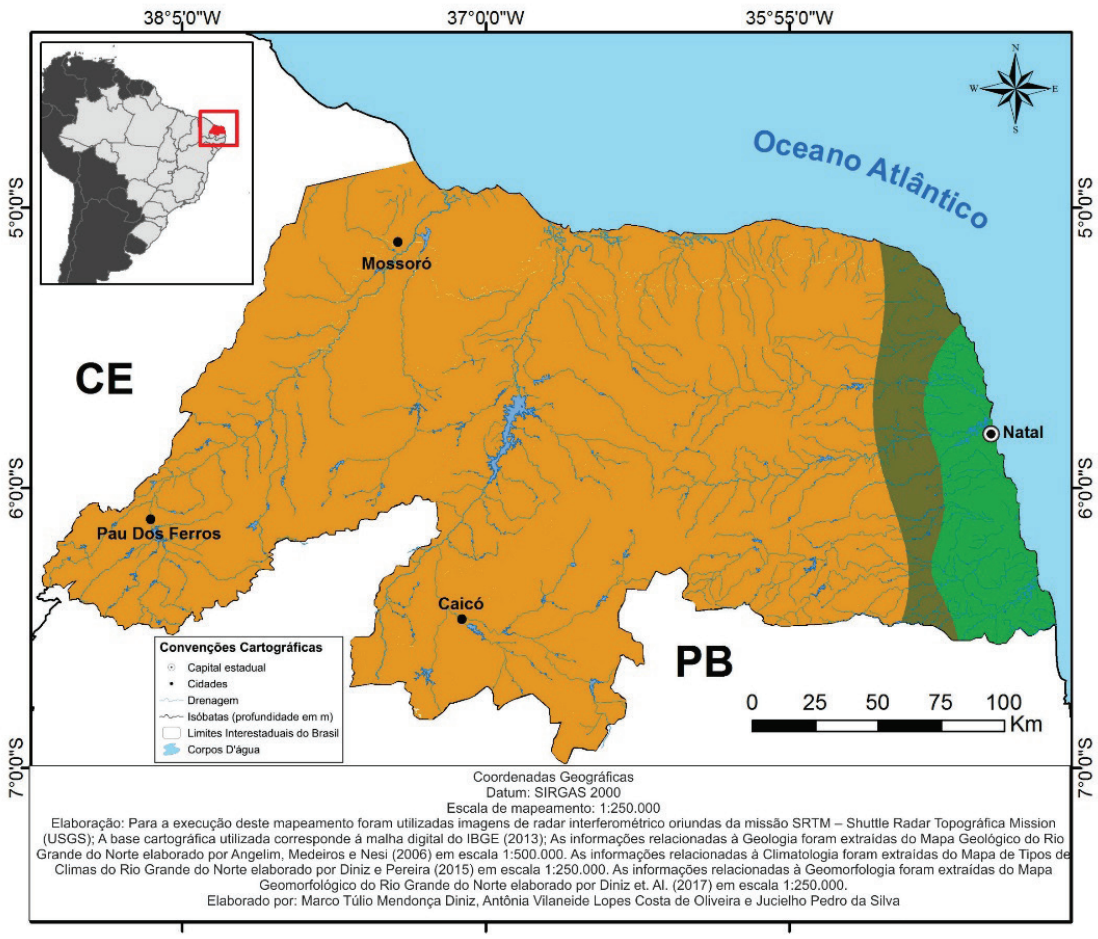

Domínios Morfoclimáticos

Domínio das depressões interplanálticas semiáridas do Nordeste (vegetado por caatingas)

(Área de transição)

Domínio dos "mares de morros" florestados

Figura 3 - Domínios Morfoclimáticos do estado do Rio Grande do Norte.

Fonte: Elaborado pelos autores (2018). 
O Domínio da Mata Atlântica no Rio Grande do Norte é predominantemente ocupado pela vegetação com influência marinha (restinga), sendo restrita a ocorrência de Floresta Ombrófila Densa (Floresta Tropical Pluvial) que caracteriza a maior parte do Domínio da Mata Atlântica ao longo do litoral oriental do país; também ocorrem redutos de Floresta Estacional Semidecidual. Existem áreas com certa predominância da Savana Estépica (Caatingas), especialmente nas proximidades da área de transição, onde se misturam espécies características dos Cerrados, das Caatingas e das Florestas Tropicais. O Domínio das Caatingas é caracterizado pela predominância da Savana Estépica, à exceção das áreas mais elevadas onde ocorrem relictos de Floresta Semidecicual.

\section{Regiões naturais}

O estado do Rio Grande do Norte tem ao todo oito regiões naturais (Figura 4). Nesse nível taxonômico, foi identificada maior participação do relevo e do embasamento geológico na delimitação das unidades.

O Domínio das Caatingas foi subdividido em quatro regiões naturais: planícies e tabuleiros costeiros semiáridos, planaltos sedimentares, planaltos cristalinos e depressões semiáridas.

Planícies e Tabuleiros Costeiros Semiáridos são áreas que correspondem ao extremo norte do estado, onde, apesar da predominância de rochas sedimentares, ocorrem também diversas formas de solos jovens como neossolos quartzarênicos, neossolos flúvicos e neossolos regolíticos. Essa alta taxa de renovação se dá pela agressividade do clima Tropical de Zona Equatorial de subtipo semiárido, que tem na torrencialidade e na concentração de chuvas algumas de suas principais características. Trata-se de terrenos planos, em forma de uma rampa suave do interior para o litoral, de cerca de $50 \mathrm{~m}$ de altitude até a cota $0 \mathrm{~m}$ junto ao oceano. 


\section{REGIÕES NATURAIS DO ESTADO DO RIO GRANDE DO NORTE}

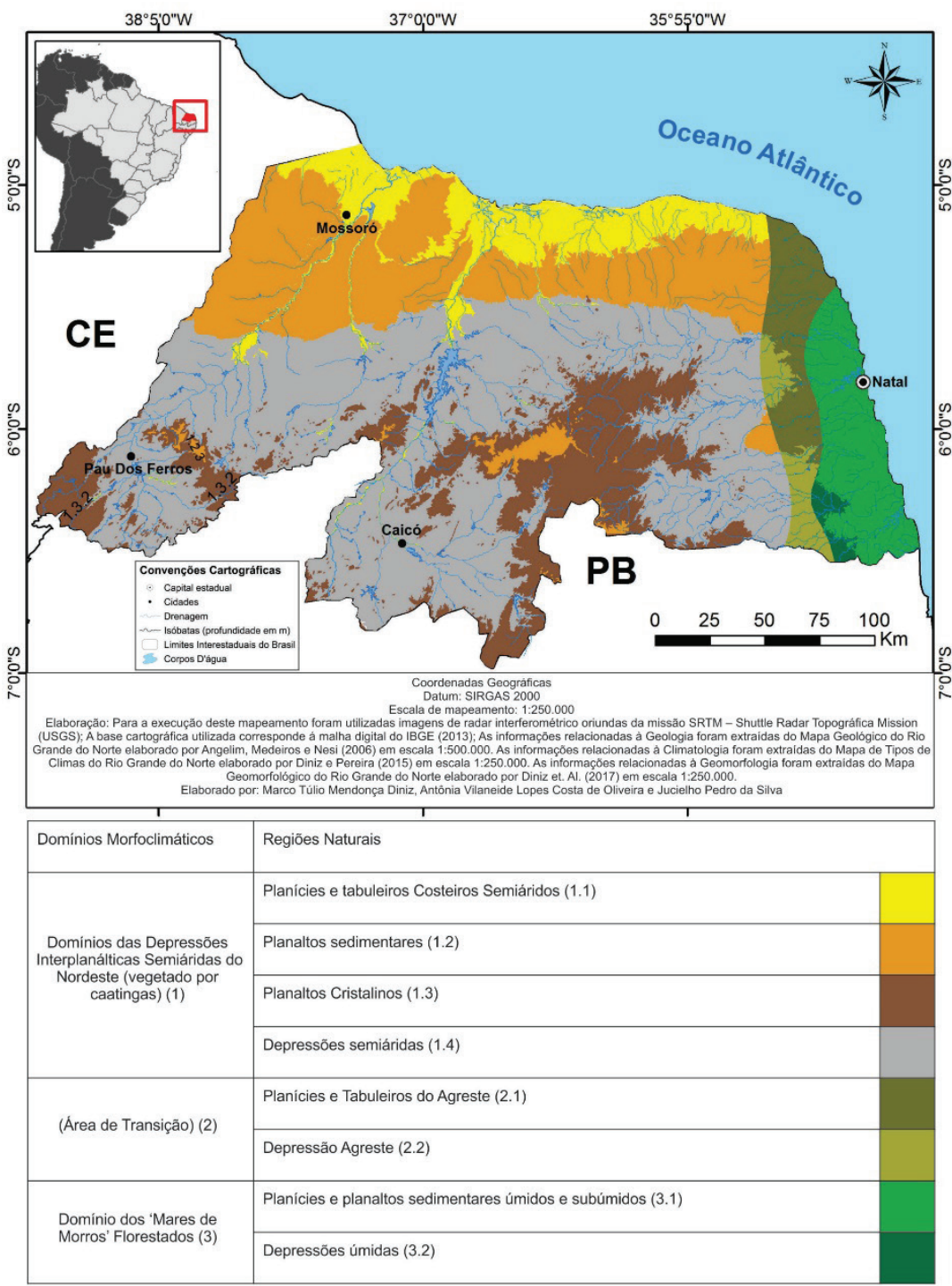

Figura 4 - Regiões naturais do estado do Rio Grande do Norte.

Fonte: Elaborado pelos autores (2018). 
Planaltos Sedimentares: essa região natural engloba as áreas de tabuleiros interiores, mais as áreas planálticas propriamente ditas de clima semiárido do Rio Grande do Norte. As altitudes são variáveis, superando os 700 m nas áreas de chapadas sobrepostas ao embasamento, que são paisagens que se desenvolvem sobre o capeamento da formação Serra do Martins por sobre o embasamento cristalino. Nessas áreas "serranas" do Rio Grande do Norte, as temperaturas médias são mais amenas, com médias anuais de $23,2^{\circ} \mathrm{C}$ em Martins, mais de $3^{\circ} \mathrm{C}$ a menos do que Caicó $\left(26,7^{\circ} \mathrm{C}\right)$, localizada a $143 \mathrm{~m}$ de altitude nos Sertões do Piranhas. Além da amenidade da temperatura, a precipitação é maior, com média de 1106,8 mm/ano na mesma Martins (Diniz; Pereira, 2015), o que proporciona a ocorrência de relicto de Floresta Estacional Semidecidual (Mata PlúvioNebular) nesse platô. No restante da área, a vegetação varia conforme o clima, predominando a Savana Estépica (caatingas) no clima semiárido forte.

Planaltos Cristalinos: essa região natural é composta pelas áreas mais elevadas sobre as rochas cristalinas no estado, variando desde cerca de 200 m de altitude no sopé da Borborema até 868 m no extremo oeste, no maciço do Pereiro. Esses terrenos têm características que variam conforme a altitude e a planimetria. Nas áreas mais aplainadas existem verdadeiros sertões suspensos, como o Seridó Oriental, nas proximidades de Currais Novos, onde as atividades humanas dominantes são as mesmas dos sertões. Já nas áreas mais escarpadas, a ocupação é rarefeita e ocorrem verdadeiros relictos de caatinga arbórea, pois nela é maior a preservação das condições naturais. O clima é semiárido brando nas áreas elevadas do oeste potiguar e mais seco nas proximidades da encosta de sotavento da Borborema.

Depressões Semiáridas: a região natural dos sertões do Rio Grande do Norte concentra ainda grande parte da população e até poucas décadas era a região econômica mais relevante do estado (Gomes, 1997; Diniz; Bernardino; Oliveira, 2015). Espacialmente é a região natural mais representativa. É uma das áreas core do Domínio das Caatingas, especialmente nos Sertões do Seridó. As características mais marcantes do domínio estão presentes nesta área, como ocupação humana com base em arcaicos sistemas agropastoris que vêm degradando as caatingas desde o século XVIII, tendo resultado na predominância de vegetação herbácea com arbustos espaçados, como na Caatinga Seridó, assim denominada por 
Kuhlmann (1977). O clima é o Tropical de Zona Equatorial, que é mais brando (seis meses secos), tanto quanto se afasta da encosta de sotavento da Borborema, onde se chega a ter nove meses secos (Diniz; Pereira, 2015).

Planícies e Tabuleiros do Agreste: essa região natural de transição não havia sido mapeada anteriormente. A região tem características comuns tanto às planícies e aos tabuleiros costeiros semiáridos como às planícies e aos planaltos sedimentares úmidos e semiúmidos.

Depressão Agreste, também com características transitórias entre as Depressões Semiáridas e Depressões Úmidas.

No Domínio da Mata Atlântica, existem duas regiões naturais:

As Planícies e Planaltos Sedimentares Úmidos e Semiúmidos estão posicionados no extremo oriental do estado. Sua característica comum são os terrenos sedimentares em clima que varia de úmido mais a leste a subúmido no contato com o agreste, o que evidencia a forte influência da maritimidade nos climas na parte oriental do estado (Diniz; Pereira, 2015).

A região natural das Depressões Úmidas não havia sido mapeada anteriormente. É uma área de terrenos cristalinos, a sudeste do estado, com clima semiúmido (quatro a cinco meses secos).

\section{Geocomplexos}

As Planícies e Tabuleiros Costeiros semiáridos têm três geocomplexos (Figura 5):

A Planície Costeira Semiárida se trata de uma subdivisão da unidade "duna” de Cestaro et al. (2007). Neste trabalho, foram consideradas três planícies costeiras, uma semiárida, outra do agreste e outra úmida. A área é composta por praias arenosas com ausência de solos. Neossolos quartzarênicos ocorrem nas dunas semifixas desse geocomplexo; ocorrem ainda extensas planícies flúvio-marinhas. A maior área estuarina é o delta do Açu, que tem mais de $220 \mathrm{~km}^{2}$ (Diniz; Vasconcelos, 2017). 


\section{UNIDADES DE PAISAGEM (GEOCOMPLEXOS) DO ESTADO DO RIO GRANDE DO NORTE}

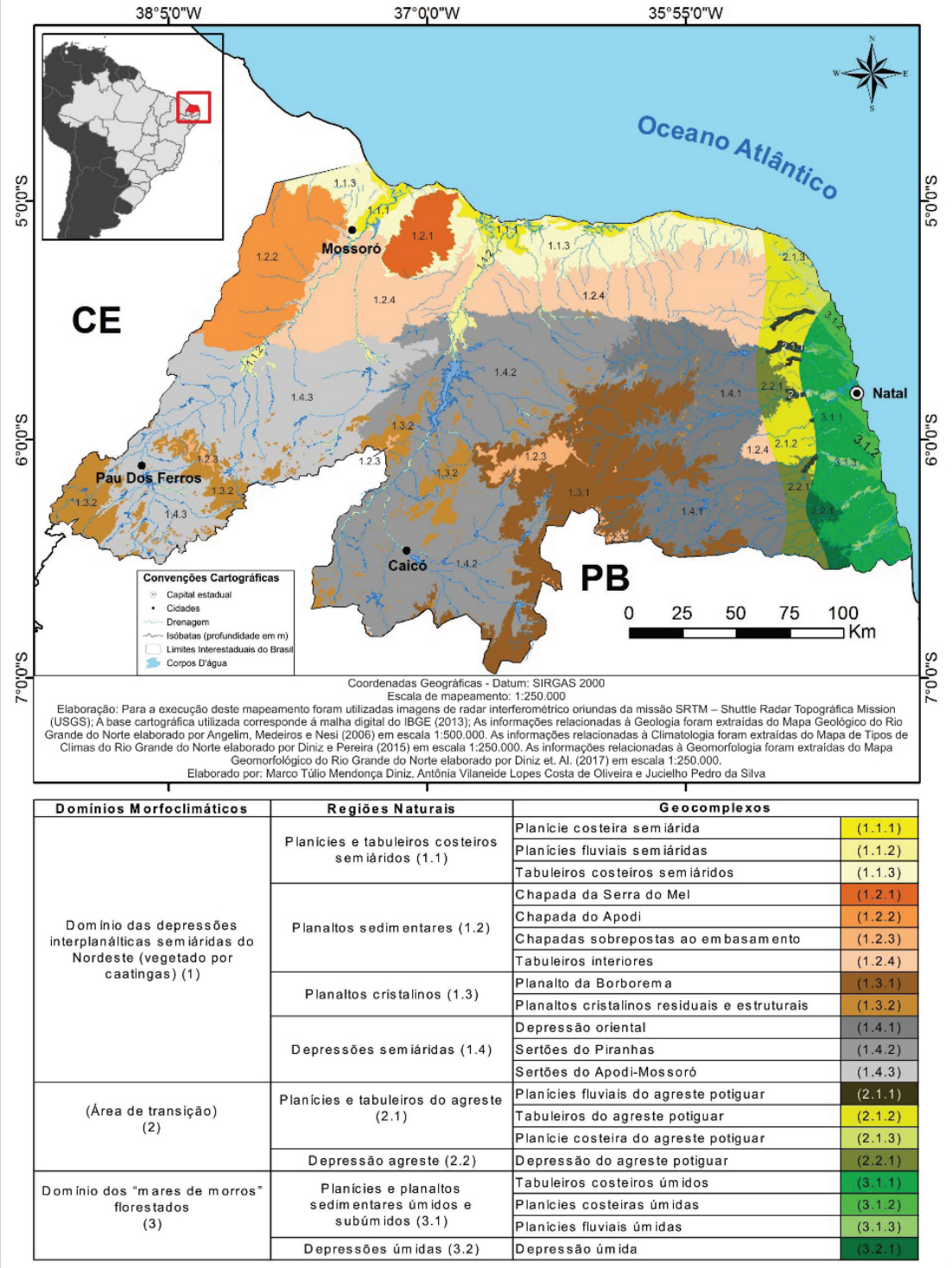

Figura 5 - Unidades de paisagem (geocomplexos) do estado do Rio Grande do Norte.

Fonte: Elaborado pelos autores (2018). 
O segundo geocomplexo é das Planícies Fluviais Semiáridas, que se trata da junção das unidades "vale lagunar" e "vale fluvial semiárido", de Cestaro et al. (2007), uma vez que se considerou que essas planícies têm características de clima, solos e vegetação idênticas. São colonizadas originalmente por mata ciliar, onde imperava a carnaúba (Copernicia prunifera), ainda bastante presente na região. Mas, nos dias de hoje, os carnaubais são intercalados por culturas de várzeas nos neossolos flúvicos da área. Essas culturas têm um marco espacial de separação importante no vale do Açu. A montante da barragem de Armando Ribeiro Gonçalvez, elas são tradicionais e de técnicas rudimentares, enquanto a jusante desse açude as atividades são altamente tecnificadas e realizadas por empresas transnacionais para a exportação dos produtos da fruticultura ali praticada.

O terceiro geocomplexo é o dos Tabuleiros Costeiros Semiáridos, que tem limites praticamente coincidentes com o "tabuleiro semiárido costeiro" da classificação anterior (Cestaro et al., 2007), áreas de relevo suave em forma de rampa que se inclinam desde $50 \mathrm{~m}$ de altitude até o contato com a planície costeira, que é quase toda em cotas abaixo de 3 m. São áreas que têm neossolos quartzarênicos nos fácies mais arenosos da Formação Barreiras; esses solos são renovados pela torrencialidade do clima. Em geral, predominam latossolos amarelos e vermelho-amarelos formados em climas úmidos pretéritos.

Esses tabuleiros têm ocupação rarefeita, pois, à exceção dos rios Apodi-Mossoró e Açu, não há outra fonte de água em superfície que sustente expressiva ocupação humana no litoral setentrional do estado.

A fonte de água para as populações locais são poços artesianos. Não existem cidades com seu território exclusivo nesse geocomplexo, à exceção de Parazinho, uma pequena cidade com pouco mais de cinco mil habitantes, o que se deve à quase ausência de água em superfície.

Os Planaltos sedimentares têm quatro geocomplexos (Figura 5). A Chapada da Serra do Mel, que não havia sido mapeada por Cestaro et al. (2007), compunha a unidade "tabuleiro semiárido costeiro" destes autores; trata-se de um domo salino (MAIA, 2012). Nessa área, a Formação Barreiras foi soerguida até $280 \mathrm{~m}$ de altitude, seriam tabuleiros suspensos com os mesmos latossolos vermelho-amarelos e demais características geoambientais também em semelhança. Sua distinção se dá pelo marcante desnível topográfico. 
O segundo geocomplexo é o da Chapada do Apodi, que não havia sido mapeada por Cestaro et al. (2007). Compunha o "tabuleiro semiárido interiorano" desses autores. Trata-se do reverso dessa chapada em forma de uma rampa suave, que diminui desde 270 até $40 \mathrm{~m}$ de altitude próximo ao vale do rio Apodi-Mossoró. São áreas tabulares formadas majoritariamente pelo calcário Jandaíra, com alguns capeamentos da Formação Barreiras, onde ocorrem vertissolos e cambissolos (Sudene, 1971). Nessas áreas, existe fruticultura irrigada em médias propriedades, principalmente no município de Baraúnas.

A terceira unidade é das Chapadas Sobrepostas ao Embasamento, com limites praticamente coincidentes com o da unidade das "chapadas" do mapeamento anterior (Cestaro et al., 2007). Essas áreas são as chamadas "serranas" no Rio Grande do Norte. São as chapadas do Monte das Gameleiras, Serra de Santana, Serra de João do Vale e Serras de Portalegre e Martins. Estas últimas são mais úmidas, pois, conforme identificado por Diniz e Pereira (2015), a umidade nas áreas do interior do Rio Grande do Norte tende a ser mais elevada tanto mais estejam essas áreas distantes da vertente de barlavento da Borborema. A temperatura média anual é em torno de $23^{\circ} \mathrm{C}$, mas é comum ela ficar abaixo dos $20^{\circ} \mathrm{C}$ em noites de inverno.

Essas chapadas são compostas majoritariamente por latossolos vermelho-amarelos, como os da Formação Barreiras, mas nessas áreas predominam as Florestas Semideciduais e Deciduais, diferente das savanas estépicas dos tabuleiros semiáridos. Tal fato se deve à maior umidade de chuvas e da própria neblina, o que permite chamar essas florestas de plúvio-nebulares.

O quarto geocomplexo dessa região natural é o dos Tabuleiros Interiores, que tem limites idênticos ao da unidade "tabuleiro semiárido interiorano" (Cestaro et al., 2007), exceto a Chapada do Apodi, que não havia sido mapeada. Esses tabuleiros são semelhantes em forma aos tabuleiros costeiros semiáridos, sendo áreas aplanadas, em forma tabular, que se inclinam desde 200 até cerca de $50 \mathrm{~m}$ de sul para norte, assim como os tabuleiros costeiros semiáridos, apresentando água em superfície nas áreas das planícies fluviais. O agravante para esses tabuleiros é que, diferentemente dos outros, aqui predomina o calcário Jandaíra em superfície, uma rocha bastante solúvel, que não acumula água em subsuperfície, a não ser em lagos subterrâneos. Assim, além de 
não haver água em superfície, a de subsuperfície é rara, o que dificulta a ocorrência de populações humanas. Os calcários também são responsáveis pela ocorrência de vertissolos, cambissolos e argissolos nesta área.

A ocupação humana que merece menção é a cidade de João Câmara, com pouco mais de 34 mil habitantes (IBGE, 2017), que tem sua dinâmica econômica mais associada à rodovia BR-406, que liga Natal à região salineira de Macau, do que às atividades produtivas locais. De resto, essas áreas são semidesertos como o redor de cidades como Angicos e Lajes.

A região dos Planaltos Cristalinos tem dois geocomplexos (Figura 5). O Planalto da Borborema (utiliza o mesmo nome e praticamente os mesmos limites do mapeamento de Cestaro et al., 2007) e Planaltos Cristalinos Residuais e Estruturais (limites semelhantes aos da unidade "planalto residual" de Cestaro et al., 2007). Ambos estão em áreas de clima semiárido, que é mais severo a sotavento da Borborema e mais brando no Maciço do Pereiro, no extremo oeste. Essas paisagens têm pelo menos dois tipos de fácies: um em áreas mais afetadas pela secular atividade pecuária e os inselbergs e escarpas serranas, onde o homem ainda não interferiu na dinâmica natural de forma decisiva. As Savanas Estépicas Gramíneo-Lenhosas (arbustivo-herbáceas) colonizam áreas de luvissolos crômicos associados a neossolos litólicos na Borborema. Nos planaltos do oeste do estado, predominam argissolos vermelhos que sustentam Savanas Estépicas Arborizadas (arbustivo-arbóreas). Esses planaltos do oeste têm clima semiárido brando (seis meses secos) nas áreas mais elevadas (acima dos $500 \mathrm{~m})$.

A região das Depressões Semiáridas tem três geocomplexos (Figura 5). A Depressão Oriental no mapeamento anterior (Cestaro et al., 2007) foi chamada "depressão subúmida Oriental" e teve seus limites alterados de acordo com os divisores de águas que drenam a área; já o termo subúmida foi retirado por se tratar de área de clima semiárido. A área drena água para os rios que deságuam no litoral oriental; são paisagens mais secas tanto mais estejam afastadas do Atlântico, uma vez que o efeito da maritimidade se faz sentir a até áreas afastadas entre 80 e $100 \mathrm{~km}$ do oceano. Nessa unidade (Diniz; Pereira, 2015), ocorrem neossolos litólicos no sopé da Borborema e planossolos associados a luvissolos crômicos nas áreas menos secas, mais a leste.

Os Sertões do Piranhas são partes da "depressão semiárida interiorana” do mapeamento anterior (Cestaro et al., 2007). São as 
superfícies deprimidas que drenam águas para o rio Piranhas e seus afluentes como o rio Seridó, área interiorana de ocupação mais antiga, que se iniciou ainda no século XVIII e, por isso, é a porção de terrenos cristalinos mais degradada do estado.

O clima é mais seco nesses sertões nas proximidades da encosta de sotavento da Borborema, como em Acari e Parelhas. Predominam os neossolos litólicos associados a manchas de luvissolos crômicos nas áreas menos degradadas, colonizados por savana estépica gramíneo-lenhosa, a Caatinga Seridó (Kuhlmann, 1977).

Os Sertões do Apodi-Mossoró (outra parte da "depressão semiárida interiorana" do mapeamento anterior de Cestaro et al., 2007)) têm solos mais preservados, com amplas áreas de argissolos vermelhos, associados a luvissolos crômicos; não raro, são encontrados perfis com mais de $2 \mathrm{~m}$ de profundidade. A drenagem superficial no alto oeste do estado (parte mais a sudoeste do território) é basicamente de alto curso do rio, onde são maiores as declividades. Existem sertões a $400 \mathrm{~m}$ de altitude, por isso a disponibilidade para a açudagem é mais restrita, o que provavelmente teria sido o fator responsável pela maior conservação dessas terras.

Os três geocomplexos têm escoamento superficial intenso quando se dão as chuvas torrenciais da estação chuvosa, devido à presença de solos de horizonte $\mathrm{B}$ textural ou mesmo de afloramentos rochosos que são naturalmente impermeáveis, o que favorece esse escoamento.

Para as planícies e tabuleiros do agreste, foram propostos três geocomplexos, até então não mapeados para esta área de transição situada entre os dois grandes domínios morfoflimáticos do estado (Figura 5), uma vez que a área de transição entre os dois domínios morfoclimáticos foi delimitada pela primeira vez nesta oportunidade:

As Planícies Fluviais do Agreste Potiguar são áreas bastante utilizadas pela atividade humana. As planícies do Ceará-Mirim e Potengi são as mais expressivas, ainda assim muito inferiores em extensão às planícies do sertão. Ao longo da ocupação do Rio Grande do Norte, o agreste tem se dedicado à produção de alimentos, com áreas de culturas como mandioca, milho e feijão.

Os Tabuleiros do Agreste Potiguar têm basicamente as mesmas atividades humanas praticadas na unidade anterior. Os latossolos estão associados aos neossolos quartzarênicos, que evoluíram sobre a Formação Barreiras e são colonizados por savana estépica gramíneo-lenhosa com 
Florestas Caducifólias, combinação típica dessas áreas de transição. A secular agricultura praticada é de baixo rendimento

A Planície Costeira do Agreste Potiguar está localizada no extremo nordeste do estado, tem extensos campos de dunas formados pelos constantes alísios de sudeste. O clima semiárido brando dessa área favorece o intenso transporte eólico, uma vez que os sedimentos da área de pós-praia têm menor coesão durante os seis meses de estiagem da área. As dunas semifixas apresentam vegetação de restingas jovens sobre os neossolos quartzarênicos, o restante da área tem ausência de solos e vegetação. São paisagens dominadas pela atividade de transporte eólico e pela ação das ondas e marés, por isso mesmo fortemente instáveis.

A região natural da Depressão Agreste tem apenas um geocomplexo, a Depressão do Agreste Potiguar (Figura 5), uma paisagem também dedicada à pecuária extensiva e à policultura de alimentos nos planossolos que predominam na área (Sudene, 1971). A diferença deste para os outros geocomplexos do agreste se dá no embasamento geológico cristalino e no tipo de solo (planossolos) diferenciado graças a esse embasamento, já que o clima é o mesmo Tropical do Nordeste Oriental, subtipo semiárido brando (seis meses secos). A ocupação humana também é semelhante aos outros geocomplexos do agreste.

A região natural das Planícies e Planaltos Sedimentares úmidos e semiúmidos apresenta três geocomplexos (Figura 5). Os Tabuleiros Costeiros Úmidos se tratam de uma redefinição dos limites do "tabuleiro subúmido oriental" do mapeamento anterior (Cestaro et al., 2007), de acordo com os aspectos do clima principalmente. São áreas da Formação Barreiras em clima úmido e semiúmido. Ao norte do rio Ceará-Mirim, tem forma tabular propriamente dita e, ao sul desse rio, são tabuleiros dissecados. Os solos variam entre os latossolos vermelho-amarelos na parte mais oeste até argissolos vermelho-amarelos nas áreas mais úmidas ao sul, onde ocorre Floresta Semidecidual, bastante degradada pela secular atividade canavieira. Ocorrem neossolos quartzarênicos nos fácies mais arenosos, que são encontrados em paleodunas na parte mais norte, colonizadas por cerrados (savana) (Sudene, 1971).

As Planícies Costeiras Úmidas são parte das unidades "duna" e "manguezal e apicum" do mapeamento anterior. Pertencem à Costa Mista de Dunas e Falésias na compartimentação do litoral do Nordeste do Brasil (Diniz; Oliveira, 2016), de modo que, na área, essas planícies 
são formadas por dunas intercaladas por falésias. As dunas migram para noroeste, carregadas pelos constantes alísios de sudeste. Elas variam desde móveis como em Genipabu até fixas como em Natal.

As Planícies Fluviais Úmidas, anteriormente denominadas "vale fluvial subúmido” (Cestaro et al., 2007), são áreas semelhantes às planícies fluviais do agreste, com pequena expressão espacial, mas importantes na produção canavieira, na qual os neossolos flúvicos tiveram quase toda a vegetação ciliar substituída pela cultura agrícola.

A região natural das Depressões Úmidas não havia sido mapeada anteriormente e tem apenas um geocomplexo, o da Depressão Úmida (Figura 5), uma área de terrenos cristalinos, a sudeste do estado, com clima semiúmido. Tem os mesmos planossolos da depressão do agreste e também é uma área de agropecuária extensiva.

\section{Considerações finais}

Neste trabalho, foram delimitadas as paisagens do estado do Rio Grande do Norte em escala de 1:250.000. Este estudo deve servir de base para o planejamento e o ordenamento do território do estado. Espera-se que possa ser o passo inicial rumo ao Zoneamento Geoambiental e EcológicoEconômico do estado (ZEE).

Os 20 geocomplexos, oito regiões naturais e dois domínios morfoclimáticos mostram a grande diversidade paisagística em uma das menores unidades da Federação. Isso se deve à sua posição no limite extremo Nordeste do continente sul-americano, o que lhe confere a ocorrência de dois tipos climáticos bastante distintos em uma área contígua, parte mais influenciada pelos climas que dominam a Costa Semiárida Brasileira (Nordeste Setentrional) e os que dominam a Costa dos Recifes (Nordeste Oriental).

Outra característica decisiva para essa diversidade paisagística é a ocorrência de duas províncias geológicas, a da Borborema e a das Bacias Marginais. As mudanças de altitude e os processos erosivos e deposicionais também são responsáveis pelas variações paisagísticas, que têm, por sua vez, grupos vegetacionais distintos como resposta à interação dos elementos supracitados.

A ocupação humana é também diversa, em grande parte se adaptando às condições naturais, uma vez que a maior parte das atividades 
humanas é de baixo desenvolvimento técnico em grande porção do território do estado.

Espera-se, com esta pesquisa, a unificação de um sistema taxonômico, que por sua vez crie uma hierarquia das unidades geoambientais do estado e de estados vizinhos, uma vez que este mapeamento tem limites coincidentes com as unidades de Souza (2000) nas áreas limítrofes com o estado do Ceará. Pretende-se, com a criação desse sistema hierárquico em diferentes escalas, que ele possa servir de embasamento para as diversas pesquisas de grande escala cartográfica.

\section{Agradecimentos}

Os Autores agradecem ao CNPq pelo financiamento desta pesquisa através da Chamada CNPq/ MCTI No 25/2015 Ciências Humanas, Sociais e Sociais Aplicadas. Agradecem ainda ao professor Luiz Antônio Cestaro, da UFRN, pela leitura e pelas sugestões.

\section{Referências}

AB' SÁBER, A. N. Um conceito de Geomorfologia a serviço das pesquisas sobre o Quaternário. Geomorfologia, São Paulo, v. 18, p. 1-23, 1969.

. Os domínios de natureza do Brasil: potencialidades paisagísticas. São Paulo: Ateliê Editorial, 2003.

ANGELIM, L. A. A, MEDEIROS, V. C., NESI, J. R. Programa Geologia do Brasil - PGB. Projeto Geologia e Recursos Minerais do Estado do Rio Grande do Norte. Mapa Geológico do Estado do Rio Grande do Norte. CPRM/FAPERN, Recife, 2006. 1 mapa color. Escala 1:500.000.

BEROUTCHACHVILI, N. L.; BERTRAND, G. Le geosysteme ou systeme territorial naturel. Revue Géographique des Pyrénés et du Sud-ouest, Toulose, v. 49, n. 2, p. 167-180, 1978.

BERTRAND, G. Paisagem e Geografia Física Global: esboço metodológico. Tradução: Olga Cruz. Cadernos de Ciências da Terra, São Paulo, USP-IGEOG, n. 43, 1972.

CAILLEUX, A.; TRICART, J. Le problème de la classification des faits géomorphologiques. Ann. de Géogr., v. 65, p. 162-186, 1956.

CESTARO, L. A.; ARAÚJO, P. C.; MEDEIROS, C. N.; CISNEIROS, R. ; ARAUJO, L. P. Proposta de um sistema de unidades geoambientais para o Rio Grande do Norte. In: SIMPÓSIO BRASILEIRO DE GEOGRAFIA FÍSICA APLICADA, 12., 2007, Natal-RN. Anais... Natal-RN: UFRN, 2007. p. 267. 
DINIZ, M. T. M.; BERNARDINO, D. B. S. M.; OLIVEIRA, G. P. Condicionantes naturais e distribuição espacial das economias fundantes do Rio Grande do Norte: sucrocultura e pecuária nos séculos XVII e XVIII. Revista GEOUECE, v. 4, n. 7, p. 126-152, 2015.

DINIZ, M. T. M.; OLIVEIRA, G. P. Proposta de compartimentação em mesoescala para o litoral do Nordeste brasileiro. Revista Brasileira de Geomorfologia, v. 17, n. 3, p. 565-590, 2016.

DINIZ, M. T. M.; OLIVEIRA, G. P.; MAIA, R. P.; FERREIRA, B. Mapeamento Geomorfológico do estado do Rio Grande do Norte. Revista Brasileira de Geomorfologia, v. 18, n. 4, p. 689-701, 2017.

DINIZ, M. T. M.; PEREIRA, V. H. C. Climatologia do estado do Rio Grande do Norte, Brasil: sistemas atmosféricos atuantes e mapeamento de tipos de clima. Boletim Goiano de Geografia, v. 35, n. 3, p. 488-506, 2015.

DINIZ, M. T. M.; VASCONCELOS, F. P. Condicionantes naturais à produção de sal marinho no Brasil. Mercator, Fortaleza, v. 16, p. 1-19, 2017.

GOOGLE. Google Earth website. Disponível em: <https://www.google.com/ earth/2018>. Acesso em: 16 jul. 2017.

GOMES, R. C. C. Fragmentação e gestão do território no Rio Grande do Norte. 1997. Tese (Doutorado em Geografia) - Universidade Estadual Paulista, Rio Claro, 1997.

IBGE. Instituto Brasileiro de Geografia e Estatística.Estados@. Disponível em: <http://www.ibge.gov.br/estadosat/perfil.php?sigla=rn>. Acesso em: 11 maio 2017.

IDEMA. Instituto de Desenvolvimento Econômico e Meio Ambiente. Unidades Geoambientais do Estado do Rio Grande do Norte. Natal, 2006.

INPE. Instituto Nacional de Pesquisas Espaciais. Topodata. Disponível em: <http://www.dsr.inpe.br/topodata/index.php>. Acesso em: 19 jun. 2017.

KUHLMANN, E. Vegetação. In: INSTITUTO BRASILEIRO DE GEOGRAFIA E ESTATÍSTICA.. Geografia do Brasil: Região Nordeste. Rio de Janeiro: IBGE, 1977.

MAIA, R. P. Geomorfologia e neotectônica no vale do rio Apodi-Mossoró RN. Natal, 2012. 218 f. Tese (Doutorado em Geodinâmica) - Programa de PósGraduação em Geodinâmica e Geofísica, Universidade Federal do Rio Grande do Norte, Natal, 2012.

SOCHAVA, V. B. O estudo de geossistemas. Métodos em questão. São Paulo: Instituto de Geografia/USP, 1977. 51 p.

SOUZA, M. J. N. de. Bases naturais e esboço do zoneamento geoambiental do estado do Ceará. In: LIMA, L. C.; SOUZA, M. J. N. de; MORAIS, J. O. de. Compartimentação territorial e gestão regional do Ceará. Fortaleza: FUNECE, 2000.

SUDENE. Superintendência do Desenvolvimento do Nordeste. Levantamento exploratório-reconhecimento de solos do estado do Rio Grande do Norte. Recife, 1971. 


\section{Contribuição dos autores}

Os dois autores contribuíram conjuntamente para o desenvolvimento da pesquisa. O autor Marco Túlio Mendonça Diniz foi o idealizador do projeto de pesquisa que resultou neste artigo. Suas contribuições foram de ordem científicas e intelectuais, além de levantamento de base cartográfica, trabalho de campo, estruturação e revisão textual. Para a autora Antônia Vilaneide Lopes Costa de Oliveira coube a tarefa de contribuir com as discussões científicas e intelectuais, mapear as unidades de paisagem, estruturar e revisar o texto apresentado.

Marco Túlio Mendonça Diniz - Possui graduação em Licenciatura Plena em Geografia, mestrado e doutorado pela Universidade Estadual do Ceará. Atualmente é Professor Adjunto III da Universidade Federal do Rio Grande do Norte. https://orcid.org/0000-0002-7676-4475

Antônia Vilaneide Lopes Costa de Oliveira - Graduada em Geografia pela Universidade Federal do Rio Grande do Norte, mestrado em Desenvolvimento e Meio Ambiente pela mesma Universidade. Atualmente é doutoranda em Geografia pela Universidade Federal do Rio Grande do Norte. https://orcid.org/0000-0001-8962-0692

Recebido para publicação em 21 de abril de 2018

Aceito para publicação em 29 de maio de 2018 